\section{Correspondence on 'Performance of the 2019 EULAR/ACR classification criteria for systemic lupus erythematosus in early disease, across sexes and ethnicities'}

We read with interest the recent work by Johnson and colleagues regarding their evaluation of the 2019 European League Against Rheumatism/American College of Rheumatology (EULAR/ACR) classification criteria for systemic lupus erythematosus (SLE) in early disease across patient groups with different ethnic background. ${ }^{1}$ Their work is important since SLE remains clinically heterogeneous, possibly due to underlying molecular diversity, ${ }^{2}$ and various sets of criteria may not necessarily perform equally well within all different populations or sexes.

To challenge new sets of classification criteria by using retrieved clinical and laboratory data from cases with confirmed disease and cases with suspected disease, and compare their performance with older classification grounds is fair, reasonable and important. In 2015, we applied the 2012 Systemic Lupus International Collaborating Clinics (SLICC-12) criteria to 243 patients with confirmed SLE from our regional cohort and 55 control subjects with possible systemic autoimmune disease and presence of $\geq 1$ SLE-related autoantibody. We concluded that SLICC-12 had advantages compared with older criteria with regard to diagnostic sensitivity, whereas we found the diagnostic specificity to be surprisingly low. ${ }^{3}$

Last year, we performed a similar evaluation of the 2019 EULAR/ACR criteria by using data from Swedish patients of which the majority had Caucasian ethnicity. We achieved comparable results for the SLICC-12 and 2019 EULAR/ACR criteria with respect to diagnostic sensitivity, specificity and accuracy. ${ }^{4}$ Johnson and colleagues refer to our paper and claim that it is inappropriate to evaluate their new criteria as 'diagnostic criteria'. In our view, these kind of comparisons are not wrong, and are exactly what they are doing themselves when comparing the performance of the ACR-97, SLICC-12 and 2019 EULAR/ACR criteria in their recent paper. ${ }^{1}$ The term 'diagnostic criteria' is however wrong, but not used by us. ${ }^{4}$ Our use of the terms 'diagnostic sensitivity' and 'diagnostic specificity', and the derived term from there 'diagnostic accuracy', should be understood in the original analytical sense, where 'diagnostic' sensitivity/specificity should be distinguished from 'analytical' sensitivity/specificity. ${ }^{5}$ Whereas 'diagnostic sensitivity' refers to the percentage of persons with a given disorder who are identified by a laboratory test, or in the present context, by a set of classification criteria, 'analytical sensitivity' refers to the smallest amount of substance that an assay can measure. The confusion between these terms may be substantial if not adding the correct adjectives, as has been discussed more than 20 years ago. ${ }^{5}$ We suggest to use the terms 'diagnostic sensitivity' and 'diagnostic specificity' in the original sense also when referring to patients classified according to criteria, and to refrain from omitting the significating adjectives, thus obscuring the language. ${ }^{5}$

In our evaluation of the 2019 EULAR/ACR criteria, 14/51 cases were misclassified as SLE and 4/60 patients were incorrectly classified as non-SLE. ${ }^{4}$ The most common diagnoses among those who were misclassified as SLE were primary Sjögren's syndrome (pSS), rheumatoid arthritis and antiphospholipid syndrome (APS). We acknowledge, however, that patients initially showing phenotypes of pSS and APS may eventually transform into SLE later on.

A fixed antinuclear antibody (ANA) titre of $\geq 1: 80$ as an entry criterion is troublesome and may affect the performance of the criteria. ${ }^{1}$ Cut-off titres for immunofluorescence (IF) ANA should be based on the 95th percentile among healthy controls, that is blood donors. Tan et al stated as early as in 1982 that an 'abnormal titre of ANA' by IF microscopy (or an equivalent assay) is required to satisfy the 'ANA criterion' of the ACR-82. ${ }^{6}$ Importantly, however, a serum dilution (titre) corresponding to the 95 th percentile among healthy referents differs across laboratories, depending on a number of variables, for example the microscope equipment, the antigen source, fluorochrome density, antigen specificity, dilution of the secondary antibodies and the subjective evaluation at ocular inspection in the microscope. ${ }^{78}$ When we for example, changed to use of light emitting diode (LED) lamps of different brands in our fluorescence microscopes in Linköping and Uppsala some years ago, both laboratories clearly noted increased fluorescence intensities in ANA samples, necessitating re-evaluation of the screening titre ('abnormal ANA titre') in healthy populations at a fixed percentage of maximal LED lamp intensity in our laboratories. These re-evaluations led to different screening titres: 200 in Uppsala and 800 in Linköping. As these differences were due to divergent local factors in our laboratories, it comes as no surprise that we thereafter obtained almost total agreement in occurrence of ANA in a defined group of patients with SLE investigated in both laboratories. ${ }^{9}$ Thus, cut-off titres for IF-ANA are, and should be, laboratory-specific, making it impossible to use the same cut-off worldwide. Thus, we find the addition of 'or an equivalent positive test' to the definition of the entry criterion in the 2019 EULAR/ACR criteria set highly relevant. Further requirement of the ANA result as 'abnormal' or 'pathological' to qualify would have been even more desired, ${ }^{8} 9$ including anti-Ro52/60 single positive individuals who often are negative in IF. ${ }^{1011}$

\section{Johan Rönnelid ๑ ,' Örjan Dahlström, ${ }^{2}$ Charlotte Dahle, ${ }^{3}$ Christopher Sjöwall ${ }^{4}{ }^{4}$ \\ 'Department of Immunology, Genetics and Pathology, Uppsala University, Uppsala, Sweden \\ ${ }^{2}$ Behavioural Sciences and Learning, Swedish Institute for Disability Research, Linköping, Sweden \\ ${ }^{3}$ Department of Biomedical and Clinical Sciences, Division of Inflammation and Infection/Clinical Immunology and Transfusion Medicine, Linköping University, Linköping, Sweden \\ ${ }^{4}$ Department of Biomedical and Clinical Sciences, Division of Inflammation and Infection/Rheumatology, Linköping University, Linköping, Sweden}

Correspondence to Associate Professor Christopher Sjöwall, Department of Biomedical and Clinical Sciences, Division of Inflammation and Infection/ Rheumatology, Linköping University, Linköping, Sweden; christopher.sjowall@liu. se

Contributors JR, ÖD, CD and CS contributed substantially to conception and design, drafted the article, gave final approval of the version to be published and agreed to act as guarantors of the work.

Funding The authors have not declared a specific grant for this research from any funding agency in the public, commercial or not-for-profit sectors.

Competing interests None declared.

Patient and public involvement Patients and/or the public were not involved in the design, or conduct, or reporting or dissemination plans of this research.

Patient consent for publication Not required.

Provenance and peer review Not commissioned; internally peer reviewed.

(c) Author(s) (or their employer(s)) 2020. No commercial re-use. See rights and permissions. Published by BMJ. 


\section{Check for updates}

To cite Rönnelid J, Dahlström Ö, Dahle C, et al. Ann Rheum Dis Epub ahead of print: [please include Day Month Year]. doi:10.1136/annrheumdis-2020-219296

Received 13 October 2020

Accepted 15 October 2020

\section{Sinked}

http://dx.doi.org/10.1136/annrheumdis-2020-219314

Ann Rheum Dis 2020:0:1-2. doi:10.1136/annrheumdis-2020-219296

ORCID iDs

Johan Rönnelid http://orcid.org/0000-0003-1186-3226

Christopher Sjöwall http://orcid.org/0000-0003-0900-2048

\section{REFERENCES}

1 Johnson SR, Brinks R, Costenbader KH, et al. Performance of the 2019 EULAR/ACR classification criteria for systemic lupus erythematosus in early disease, across sexes and ethnicities. Ann Rheum Dis 2020;79:1333-9.

2 Sandling JK, Pucholt P, Hultin Rosenberg L, et al. Molecular pathways in patients with systemic lupus erythematosus revealed by gene-centred DNA sequencing. Ann Rheum Dis 2020:9:annrheumdis-2020-218636.
3 Ighe A, Dahlström Örjan, Skogh T, et al. Application of the 2012 systemic lupus international collaborating clinics classification criteria to patients in a regional Swedish systemic lupus erythematosus register. Arthritis Res Ther 2015;17:3.

4 Dahlström 0̈, Sjöwall C. The diagnostic accuracies of the 2012 SLICC criteria and the proposed EULAR/ACR criteria for systemic lupus erythematosus classification are comparable. Lupus 2019;28:778-82.

5 Saah AJ, Hoover DR. "Sensitivity" and "specificity" reconsidered: the meaning of these terms in analytical and diagnostic settings. Ann Intern Med 1997;126:91-4. 8992938.

6 Tan EM, Cohen AS, Fries JF, et al. The 1982 revised criteria for the classification of systemic lupus erythematosus. Arthritis Rheum 1982;25:1271-7.

7 Sjöwall C, Sturm M, Dahle C, et al. Abnormal antinuclear antibody titers are less common than generally assumed in established cases of systemic lupus erythematosus. J Rheumatol 2008:35:1994-2000.

8 Agmon-Levin N, Damoiseaux J, Kallenberg C, et al. International recommendations for the assessment of autoantibodies to cellular antigens referred to as anti-nuclear antibodies. Ann Rheum Dis 2014;73:17-23.

9 Frodlund M, Wetterö J, Dahle C, et al. Longitudinal anti-nuclear antibody (ANA) seroconversion in systemic lupus erythematosus: a prospective study of Swedish cases with recent-onset disease. Clin Exp Immunol 2020;199:245-54.

10 Reichlin M. Ana negative systemic lupus erythematosus sera revisited serologically. Lupus 2000;9:116-9.

11 Dahle C, Skogh T, Åberg AK, et al. Methods of choice for diagnostic antinuclear antibody (ANA) screening: benefit of adding antigen-specific assays to immunofluorescence microscopy. J Autoimmun 2004;22:241-8. 